\title{
From Copenhagen to Nyborg 2022: take the Tour de France Route to \#WCSPT2022
}

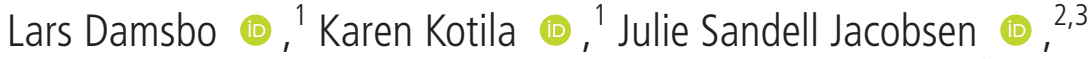

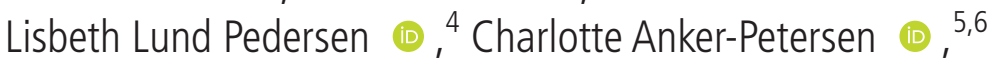 \\ Michael Skovdal Rathleff, ${ }^{7}$ Thomas Bandholm ${ }^{10},{ }^{8}$ Kristian Thorborg ${ }^{9}$
}

It is finally time to meet again in person. Danish Society of Sports Physical Therapy (DSSF) is busy organising \#Sportskongres2022 in Copenhagen (3 February 2022-5 February 2022) and \#WCSPT2022 in Nyborg (26 August 2022-27 August 2022). As the front cover of this BJSM issue illustrates, you can take the 2022 Tour de France Route from the venue of \#Sportskongres2022 (https:// www.sportskongres.dk/) in Copenhagen, city of the first stage of Tour de France (https://letourcph.dk/en) to the finish line of the second stage in Nyborg, the city that will host \#WCSPT2022 (www.wcspt. org). You will cross the beautiful Great Belt over the second longest suspension bridge in the world. The symbolism is clear, sports PT and Sports medicine will reunite and meet in person in 2022 .

\section{ROOM FOR DISCUSSION AND \\ REFLECTION}

WCSPT is a collaboration between IFSPT and a national member organisation-this time DSSF. It is our goal for \#WCSPT2022 to make room for discussion and reflection on how to apply new knowledge into a clinical setting. The overarching theme is 'Translating science

\footnotetext{
${ }^{1}$ Danish Society for Sports Physical Therapy, Odense, Denmark

${ }^{2}$ Research Centre for Health and Welfare Technology, Programme for Rehabilitation, VIA University College, Aarhus, Denmark

${ }^{3}$ Research Unit for General Practice, Aarhus, Denmark ${ }^{4}$ Danish Society of Sports Physical Therapy, Odense, Denmark

${ }^{5}$ Sports Orthopedic Research Center (SORC-C), Department of Orthopedic Surgery, Hvidovre Hospital, Hvidovre, Denmark

${ }^{6}$ Hvidovre, Denmark

${ }^{7}$ Department of Clinical Medicine, Aalborg University Hospital, Aalborg, Denmark

${ }^{8}$ Department of Clinical Research, Copenhagen University Hospital, Copenhagen, Denmark

${ }^{9}$ Department of Orthopaedic Surgery, Sports Orthopedic Research Center (SORC-C), Amager-Hvidovre Hospital, Faculty of Health Sciences, Copenhagen University, Copenhagen, Denmark
}

Correspondence to Lars Damsbo, Danish Society for Sports Physical Therapy, Odense C, Denmark; Id@sportsfysioterapi.dk into Practice'. The great facilities for the congress allow five parallel sessions of applied science to run twice during the congress, all focusing on translation and implementation of some of the topics/presentations given in the main auditorium.

The extensive congress programme leaves room for active reflection and networking in a 2-hour lunch and activity break, where we invite participants to take part in different activities. We have partnered with local organisations to allow you to engage in physical and social activities such as mountain biking, paddle boarding, beach volley and other kinds of outdoor fitness, or simply enjoy leisurely outings and conversations by the waterfront.

We hope this facilitates a beautiful combination of physical activity, knowledge sharing, reflection and networking with peers.

\section{PHYSICAL ACTIVITY AS MEDICINE}

In this BJSM issue, authors of an original paper conclude that the proportion of time spent in moderate to vigorous physical activity is significantly associated with lower risk of all-cause mortality (see page 1277). Physical activity is 'medicine', but implementation is still lacking! On the premise that active involvement enhances learning we introduce the concept: 'Do as I say and do as I do'! at \#WCSPT2022. We implore you to take an active part in the physical activities during the event and lead the way for your patients.

\section{GENDER DIVERSITY: BE INTENTIONAL}

In the 2020 Danish issue of BJSM (https:// bjsm.bmj.com/content/54/23) we prioritised gender diversity. ${ }^{1}$ On this note, we aim for gender balance at \#WCSPT2022, with $53 \%$ of scheduled speakers being women. The scientific committee for \#WCSPT2022 started off as 50-50 gender balance, but is now $40 \%$ women as the day job workload for one female changed and prevented her to continue. The editors of this BJSM issue are also chosen based on 50-50 gender balance, and the speakers at \#Sportskongres2022 are $43 \%$ women $/ 57 \%$ men. DSSF continues to strive for gender balance and encourages other congresses and journals to be intentional in the act of balancing gender topics and speakers. ${ }^{1}$

\section{UPDATE YOUR CLINICAL SKILLS}

This issue of BJSM also emphasises the importance of translating science into clinical practice. Lasse Ishøi et al present a statement paper commissioned by DSSF on FAI and labral injuries (see page 1301). This paper provides an in-depth analysis and grading of the evidence on the diagnosis and non-operative treatment of FAI/ labral injuries. This issue also includes a multidisciplinary consensus guideline by Smith and colleagues on return to sport decisions after acute lateral ankle distortion with contributions from members of DSSF (see page 1270).

Given the physical changes that occur during pregnancy and childbirth, women are at risk of not returning to running activities post partum. An original paper led by Isabel Moore has investigated factors associated with the successful return to running activities after pregnancy, and factors associated with not returning to running activities (see page 1286).

\section{CLINICAL TAKE-HOME MESSAGES}

Infographics are a growing media for the clinician and the patient to use in an educational manner. This edition brings two fantastic Infographics by Winters (see page 1311) and Getgood (see page 1313) highlighting important take-home messages on patellofemoral pain and sex differences for ACL injury. At \#WCSPT2022, there will be an infographic competition, where all abstracts are to be submitted together with an accompanying infographic. The infographics will focus on clinical take-home messages in a visually appealing form. To further facilitate clinical uptake of the best presented science, the best-rated infographics will be printed in postcard format for delegates to exchange and bring back home for their clinic wall. Our hope is that this new initiative will facilitate scientific translation and add value for sports medicine practitioners worldwide.

We hope to see you in Denmark in 2022 ! 


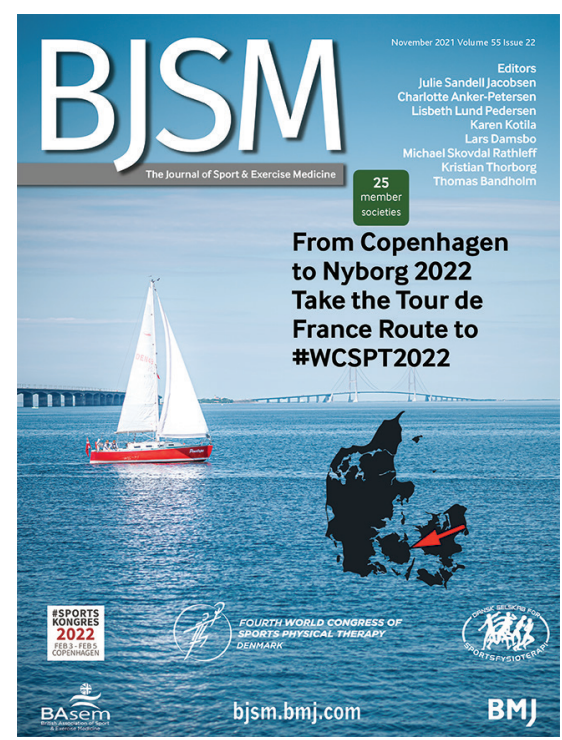

Twitter Karen Kotila @karenkotila, Julie Sandell

Jacobsen @Julie S Jacobsen, Charlotte Anker-

Petersen@C_AnkerPetersen and Thomas Bandholm @TBandholm

Collaborators The Danish Society of Sports Physical Therapy.

Contributors First author LD has written the Warm Up with contribution from the other authors and with joint responsibility.

Funding The authors have not declared a specific grant for this research from any funding agency in the public, commercial or not-for-profit sectors.

Competing interests None declared.

Patient consent for publication Not applicable.

Provenance and peer review Commissioned; internally peer reviewed.

(c) Author(s) (or their employer(s)) 2021. No commercial re-use. See rights and permissions. Published by BMJ.

Check for updates
To cite Damsbo L, Kotila K, Jacobsen JS, et al. Br J Sports Med 2021;55:1241-1242.

Accepted 15 September 2021

Br J Sports Med 2021:55:1241-1242. doi:10.1136/bjsports-2021-104987

\section{ORCID iDs}

Lars Damsbo http://orcid.org/0000-0002-2288-5220 Karen Kotila http://orcid.org/0000-0001-7624-6638 Julie Sandell Jacobsen http://orcid.org/0000-00023323-3631

Lisbeth Lund Pedersen http://orcid.org/0000-0002-

3283-622X

Charlotte Anker-Petersen http://orcid.org/0000-00025598-5682

Thomas Bandholm http://orcid.org/0000-0001-68841971

\section{REFERENCE}

1 Thorborg K, Krohn L, Bandholm T, et al. 'More walk and less talk': changing gender bias in sports medicine. $\mathrm{Br} J$ Sports Med 2020;54:1380-1. 